\title{
Impact of Educational Self-Efficacy Enhancement Program on Quality of Life, Pain Management, Self- Efficiency Behaviors and Its Impact of Satisfaction among Adults Diabetic Patients with Peripheral Neuropathy Pain: A Randomized Control Trial
}

Jawad AHMAD Abu-Shennar ( $\sim$ JAWAD_0799@YAHOO.COM )

Near East University https://orcid.org/0000-0002-0505-5356

Nurhan Bayraktar

Near East University: Yakin Dogu Universitesi

\section{Research}

Keywords: Diabetic peripheral neuropathy pain, self-efficacy, quality of life, patient satisfaction.

Posted Date: February 4th, 2021

DOI: https://doi.org/10.21203/rs.3.rs-160487/v1

License: (c) (1) This work is licensed under a Creative Commons Attribution 4.0 International License. Read Full License 


\section{Abstract}

Background: Peripheral neuropathy pain is common among adult diabetic patients worldwide. Lifestyle behavior modification such as proper diet and exercise, quitting smoking, weight control and regular follow up, as well as enhancement of self-efficacy among adult diabetic patients can be helpful in managing peripheral neuropathy pain and, therefore, improving their quality of life and satisfaction.

Aims: This study aims to investigate educational self-efficacy enhancement program's impact on pain management, self-efficiency behaviors, quality of life and satisfaction among adult diabetic patients with peripheral neuropathy pain.

Materials and Methods: This randomized controlled study was conducted between October and March 2020 at the Jordanian Ministry of Health settings, where 72 adult diabetic patients with peripheral neuropathy pain were randomly assigned into research group $(n=36)$ or control group $(n=36)$, after obtaining ethical approval and informed consents. An educational self-efficacy enhancement program was implemented in the research group only. The instrument used for data collection consisted of Demographic Data Form, Diabetes Pain Intensity Scale, Self-Efficacy Scale, Quality of Life Questionnaire (EQ-5D) and Patient Satisfaction Questionnaire.

Results: Statistically significant improvements in pain levels $(p=0.020)$, self-efficacy score $(p=0.000)$, quality of life scores $(p=0.000)$ and best imagined health status $(p=0.000)$ were found among research group participants. Furthermore, multiple-linear regression models showed that the implementation of educational self-efficacy enhancement program significantly increased the explained variance of self-efficacy scores $\left(R^{2}=0.746, p=0.000\right)$ and quality of life scores $\left(R^{2}=0.746, p=0.000\right)$. At the end of implementation, research group participants showed a high overall satisfaction levels (4.33 out of 5 ).

Conclusion: The findings suggest that an educational self-efficacy enhancement program is effective in modifying adult diabetic patients' lifestyle, enhancing self-efficacy behaviors, managing peripheral neuropathy pain, improving quality of life and satisfaction among adult diabetic patients. It is, therefore, recommended to expand the implementation of this program among adult diabetic patients with peripheral neuropathy pain.

\section{Introduction}

Diabetic peripheral neuropathy pain (DPNP) is one of the most popular and complex chronic diseases [1-3]. The American Pain Society (APS) defines DPNP as an emotional and unpleasant experience related to acute or potential tissue damage or described in terms of such damage. The nature of peripheral neuropathy pain is characterized by aching, burning, or shooting [4]. A study in the UK by Hall and colleagues (2013) estimated the incidence of DPNP at 15.3 cases per 100,000 person-years in the primary care population in 2002 and increasing to 27.2 cases per 100,000 people in 2005 [5]. Roughly, more than $11 \%$ of patients with diabetic peripheral neuropathy worldwide are suffering from DPNP [6].

Usually, DPNP is reported to interfere with daily living activities, mood, mobility, social relations and work. Moreover, impaired patients' health could hurt the patients' quality of life (QoL). Having DPNP causes higher societal and health care costs compared to diabetes without neuropathic pain ${ }^{6}$. Also, glycemic blood level plays an important role in the DPNP onset and development and although drug therapy and rehabilitation cause relative improvements and control of hemoglobin glycosylated $(\mathrm{HbA} 1 \mathrm{c})$, they are very important in the prevention of the disease complications [7-10]. 
Self-care behaviors of DPNP patients can alleviate severe symptoms; enhance pain management, clinical outcomes and quality of life; and reduce further hospitalizations [7,8,10-15]. Several factors can affect the patients' self-care including the behavior and self-efficacy of an individual [16-19]. Self-efficacy reflected the main principle of social cognition on the theory that was originally proposed by Bandura. Self-efficacy behaviors are described as one's belief in her/ his capabilities to fulfill expectations and tasks to reach the goals [20]. Furthermore, it should be noted that education plays an important role in enhancing and improving the function of an individual's behavior. In order to guide positive change in DPNP patients' self-care behavior, educational programs are developed and implemented, such as educational self-efficacy enhancement program, which plays an important role in improving health outcomes of DPNP patients. Namely, implementing an educational self-efficacy enhancement program may lead to improvements in patients' pain management, self-efficiency behaviors, quality of life and satisfaction.

To the date of writing this study, the prevalence of DPNP has been scarcely studied in Jordan. Also, an educational self-efficacy enhancement program has not been implemented on DPNP patients in Jordan. The significance of this study lies in the potential of testing this program's effectiveness in improving Jordanian DPNP patients' pain management, self-efficiency behaviors, quality of life and satisfaction for the first time. Ultimately, testing the effectiveness of the educational self-efficacy enhancement program can inform future research and practice in DPNP management in Jordan.

Therefore, this study aims to investigate educational self-efficacy enhancement program's impact on Jordanian DPNP patients' pain scores, self-efficiency behaviors, quality of life scores and satisfaction. To achieve the study's aim, the following four research questions were addressed: Is implementing an educational self-efficacy enhancement program effective in improving pain scores among adult Jordanian DPNP patients? Is implementing an educational self-efficacy enhancement program effective in improving self-efficiency scores among adult Jordanian DPNP patients? Is implementing an educational self-efficacy enhancement program effective in improving QoL scores among adult Jordanian DPNP patients? And what is the level of program satisfaction among adult Jordanian DPNP patients who received an educational self-efficacy enhancement program?

\section{Materials And Methods}

\section{Study Design}

This study employed a randomized, controlled study design, where adult Jordanians with DPNP were randomly assigned to one of two groups; a research or control group. Study participants in the research group received an educational self-efficacy enhancement program; whereas those in the control group did not. Both study groups participants have been tested for pain at the beginning and the end of the study. Also, self-efficiency behaviors, quality of life scores and satisfaction were tested in both groups at the end of the study and comparisons of these outcomes were carried out to test the impact of educational self-efficacy enhancement program implementation on these outcomes between the two groups.

\section{Setting and Sample}

Data collection took place in three Jordanian Ministry of Health $(\mathrm{MoH})$ hospitals. Each of these hospitals regularly receives diabetic complications referrals from other $\mathrm{MoH}$ hospitals and hospitals from other health sectors in Jordan, such as the private and educational sectors. The reference population of this study was all adult Jordanian DPNP patients who visited or were referred to $\mathrm{MoH}$ hospitals. Data collection took place during the period from Oct 14, 2019 - Mar 14, 2020. Inclusion criteria for selecting the study sample included being an adult Jordanian (aged 
18 years or older) with DPNP, who did regular follow-up in any of the three MoH hospitals for at least six months. The total sample size was 72 adult DPNP patients, 36 of them were randomly assigned to each of the research and control groups.

\section{Research Instruments}

A five-part assessment tool package was utilized for data collection. The five parts were: (1) demographic data developed by researchers. (2) the Diabetes Self-Efficacy Scale (DSES), a tool introduced by the Stanford SelfManagement Resource Center (SMRC) in 2009, which includes eight items rated along a five-point Likert scale (from 1 = to corresponded to never self-efficacy to $5=$ to very good self-efficacy) [21]. Scores ranged from 0 to 10 and higher scores were correlated with better self-care. Al-Amer et.al performed reliability and validity (2016) in Jordan and was taken into consideration. The DSES was translated into Arabic, with the revised scale of Cronbach's alpha that was 0.81 [22]. (3) a Quality-of-Life Scale entitled EQ-5D [23]. This standardized instrument includes four domains that measure the QoL: anxiety/depression, usual activities, mobility and self-care. The overall score was $1=$ perfect health and $0=$ dead [23]. The researcher translated the EQ-5D and two professional academic instructors- working in the field of nursing - to ensure the consistency of inquiring the information while interviewing the patients. The Jordanian EQ-5D validity and reliability researches were performed by Abu-Shennar et.al. in 2020. The revised scale of Cronbach's alpha 0.88 [24]. (4) Pain Intensity Scale, where each patient was asked to point to the number that represents the intensity of his current pain experience. According to our authors in the current research, responses were rated on a scale from 0 to 10 were less than or equals to 3 indicating mild pain, four-seven indicating moderate pain and eight-ten indicating severe pain. (5) the patient satisfaction questionnaire to assess and measure the program efficiency and effectiveness and education tools. The satisfaction scale consists of ten items, which was prepared by the researchers. According to the authors, responses were rated on a scale from one to five where one $=$ never, two $=$ low, three $=$ moderate, four $=$ good and five = very good; to determine whether further training is required during the education program in sessions.

To test the five-part assessment tool's usability, pilot research was conducted on $10 \%$ of sample members before the beginning of the study. According to the results of the pilot study, some necessary edits and revisions were made to the assessment tool.

\section{Intervention Program}

The educational self-efficacy enhancement program is specially designed for adult DPNP patients. The educational tools included demonstrative pictures, a booklet, videotapes were prepared and the programs were organized. The researchers prepared this program based on the relevant literature $[2.3,10-12,25]$ and it involved four sessions of self-efficacy enhancement and rehabilitation for each patient group. After all, the educational tools and program developed by three specialized persons (three professionals: one with a Ph.D. in nursing, one in medicine and one with a Ph.D.in pharmacy \& toxicology specializes), were reviewed and approved, following the below content:

- Information about diabetes mellitus and DPNP.

- Diabetes complications; prevention of through self-care.

- Compliance with medication, diet and exercises.

- Self-monitoring and regular follow-up. 


\section{Implementation}

The intervention program was implemented for the research group during the period Oct 14, 2019 - Mar 14, 2020, as follows:

\section{Research group:}

- Pre-tests of the outcomes through face-to-face structured interviews were performed with the research group participants individually. These interviews took place in the three $\mathrm{MoH}$ hospitals whilst participants waited in their turn in the follow-up clinic visits. In addition to the Numeric Pain Rating Scale (NRS), the interviews also collected data on demographics, QoL (EQ-5D) and Self-Efficacy for Diabetes Questionnaire (DSES).

- Educational sessions were performed. The intervention is consisting of small groups (eight to ten patients) of structured educational sessions for the enhancement programs on the quality of life of adult DPNP diabetic patients. The educational sessions were one hour to 90 minutes. Training booklets and PowerPoint presentations were used for educating the participants.

- A review was repeated in this phase of the mentioned material and an educational booklet was handed to the research group which comprised the material presented in the four-session period.

- The evaluation of the self-efficacy training program on DPNP among adult diabetic patients is carried out after three months of the education enhancement program. The Numeric Pain Rating Scale (NRS), Self-Efficacy for Diabetes Questionnaire (DSES), Quality of Life Questionnaire (EQ-5D) and Patient Satisfaction Questionnaire were implemented.

\section{Control Group:}

Pre-tests of the outcomes through face-to-face structured interviews were performed with the research group participants individually. These interviews took place in the three $\mathrm{MoH}$ hospitals whilst participants waited in their turn in the follow-up clinic visits. In addition to the Numeric Pain Rating Scale (NRS), the interviews also collected data on demographics, QoL (EQ-5D) and Self-Efficacy for Diabetes Questionnaire (DSES). No educational sessions were conducted in this group.

\section{Statistical analysis}

Statistical Package for Social Sciences (SPSS, version 25) was utilized for statistical analysis of results. Sample characteristics were tested using descriptive statistics, such as frequencies and percentages in categorical variables, means and standard deviations ( $($ SD) for continuous variables and Chi-square and Independent-Sample T-Tests were respectively used to compare the two groups in terms of demographic characteristics. To answer the first research question, Paired-Samples T-Test was used. To answer the second and third research questions, both Paired-Samples T-Tests and multiple-linear regression models were used and to answer the fourth research question, descriptive statistics, such as frequencies and percentages in categorical variables, means and standard deviations $( \pm S D)$ for continuous variables were used. The Spearman's Rank-Order Correlation Coefficient (Spearman's Rho) measures the direction and strength of the correlation among the two variables were used. In the inferential statistics of Paired-Samples T-Test, multiple-linear regression models and Spearman's rho correlation coefficients model, a p-value $<0.05$ was considered to be statistically significant. 


\section{Ethical Considerations}

Data were collected after approval by the ethical committee in the Jordanian Ministry of Health and Near East University (N.E.U). We have got approval from SMRC to apply the DSES as all rights were reserved and reproduced. The data was used for scientific inquiries only. Since the research was based on data obtained from structured questionnaires and medical records, no harm to adult DPNP diabetic patients was expected. Verbal consent was obtained from study participants before data collection and they were guaranteed information confidentiality.

\section{Results}

\section{Sample Characteristics}

In this randomized controlled study, the results of the participants' demographic characteristics revealed that the ages mean was 60.9 years of the control group and 66.3 years of the research group. More than half of the participants were male in both groups (control group: 63.9\%, research group: $75 \%$ ). $38.9 \%$ of the control group participants and $33.3 \%$ of the research group participants had a bachelor's degree or higher. All of the patients in both groups reported non-adherence to the diet regimen and were non-compliant to physical activity. Also, 30.6\% of the control group participants and $38.9 \%$ of the research group participants were current smokers. The mean body mass index (BMI) (Kg/m2) was 39.44 among the control group participants and 37.59 among the research group participants. Also, the mean monthly family income in the control group was JD 385.3 and among the research group was JD 338.5. None of the aforementioned demographic characteristics was found to be significantly different between the two groups, indicating an effective random assignment of group members (Table 1).

\section{Preeducation Evaluation}

The results of the pre-educational evaluation of the entire sample $(\mathrm{N}=72)$ and the pain levels of the patients in a pre-educational evaluation, revealed that the mean score of the participants was 6.68 out of 10 . The overall selfefficacy score was 1.60 out of 5 , while the scores for self-efficacy questions were 1.39, 1.57, 1.51, 1.73, 1.50, 1.74, 2.04 and 1.71 respectively, where a lower score indicates more pain. The overall QoL score was 2.12 out of 4, while the mobility domain score was 1.92 , self-care domain score was 2.22 , activity domain score was 2.72 , discomfort domain score was 2.92 and depression domain score was 1.31, where a lower score indicates poorer QoL. Finally, the best health imagined score was 61.11 out of 100 , where a lower score indicates poorer imagined health status (Table 2).

\section{Posteducation Evaluation}

As shown in Table 3, a dependent-sample t-test was conducted to assess the improvements in the overall NRS score, QoL scores and self-efficacy scores among the study group members $(\mathrm{N}=36)$. The results revealed that the study group members have shown a statistically significant improvement in their NRS scores (t-test $=5.694, p=$ 0.02), QoL overall scores (t-test $=176.242, p=0.000$ ) and self-efficacy overall score (t-test $=386.545, p=0.000)$. Furthermore, statistically significant improvements in every subdomain (mobility, self-care, activity, discomfort and depression) of the QoL instrument and in every question (Q1 through Q8) of the self-efficacy instrument were observed.

In order to assess the impact of educational intervention on self-efficacy score, a two-step multiple linear regression model (Table 4) was conducted on the whole sample ( $N=72)$, where self-efficacy score was entered as 
the dependent variable and age, gender, income and type of treatment were entered in the first step as independent factors. The results of the first step of the multiple linear regression model showed that the combination of age, gender, income and type of treatment were unable to significantly explain variance in self-efficacy score (Step 1 ANOVA $\left._{(d f)}=0.253_{(4)}, p=0.906\right)$ and the percentage of explained variance of step 1 of the model was very small (Step $\left.1 \mathrm{R}^{2}=0.034\right)$. However, after adding the educational intervention in the second step of the multiple linear regression, the model became statistically significant (Step 2 ANOVA $_{(d f)}=16.448(5), p=0.000$ ) and the percentage of explained variance in self-efficacy score noticeably increased (Step $\left.2 R^{2}=0.746\right)$. The statistically significant improvement in the multiple linear regression model's percentages explained variance $\left(R^{2}\right)$ indicates that the implementation of the educational intervention significantly improves self-efficacy scores among adult diabetic patients with DPNP.

Similarly, to assess the impact of educational intervention on QoL score, a two-step multiple linear regression model (Table 5) was conducted on the whole sample ( $\mathrm{N}=72)$, where QoL score was entered as the dependent variable and age, gender, income and type of treatment were entered in the first step as independent factors. The results of the first step of the multiple linear regression model showed that the combination of age, gender, income and type of treatment were unable to significantly explain variance in QoL score (Step 1 ANOVA F (df) $=1.056_{(4)}, p$ $=0.396)$ and the percentage of explained variance of step 1 of the model was small (Step $\left.1 \mathrm{R}^{2}=0.127\right)$. However, after adding the educational intervention in the second step of the multiple linear regression, the model became

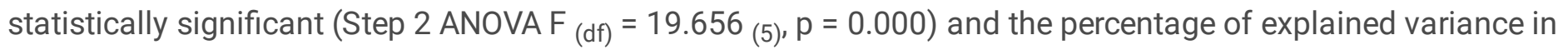
QoL score noticeably increased (Step $2 \mathrm{R}^{2}=0.778$ ). The statistically significant improvement in the multiple linear regression model's percentages explained variance $\left(R^{2}\right)$ indicates that the implementation of the educational intervention significantly improves QoL score among adult diabetic patients with DPNP.

In order to test the mutual correlation between outcome variables, Spearman's rho correlation coefficients between pain score, self-efficacy score and QoL score were conducted both in the pre-educational and post-educational evaluation. In pre-educational evaluation, none of the three outcomes was found to have a statistically significant correlation with the others. Whereas in the post-educational evaluation, the correlation was found statistically significant between self-efficacy score and QoL score (Spearman's rho $=-0.759, p=0.000$ ), but pain score's correlation with self-efficacy score and QoL score was not statistically significant (Table 6).

Finally, results showed that the satisfaction score mean of the research group participants was $4.33( \pm 0.67)$ at the end of the implementation, indicating a high level of satisfaction upon the completion of the educational program intervention (Table 7).

\section{Discussion}

The results of this randomized controlled study, which was conducted to investigate the impact of educational selfefficacy enhancement programs on pain management, self-efficiency behaviors, quality of life and satisfaction among adult DPNP diabetic patients, revealed the educational self-efficacy enhancement program was effective.

\section{Self-efficacy}

In a pre-educational evaluation of the self-efficacy behaviors, results of the patients' evaluation levels revealed that the self-efficacy behaviors scores mean for both participant's groups were showing low levels. These results were concordant with those from other epidemiological researches [7,8,10-15], where patients with DM had significantly 
lower self-efficacy behaviors than those without DM. This might be attributed to the association with lower levels of self-efficacy behaviors by lower knowledge of the patients about the disease with uncontrolled of the complications and poor self-management skills practicing, which lead to the negative feedback that was frequently implemented among DPNP patients.

In our research, the research group participants who attended the educational self-efficacy enhancement program reported a positive enhanced self-efficacy behavior by comparing the posttest and pretest mean. The essential findings of this research suggest the importance of incorporating self-efficacy enhancing interventions in diabetes self-efficacy (DSE) programs, emphasizing the requirement to build confidence for a given self-management behavior such as a portion of the health care providers communication or a component of a counseling, educational and skill-building program that can enhance the likelihood of maintaining the preferred outcomes of DPNP. Diabetes nurse educators and other health care providers need to develop effective methods for promoting self-management among adult Jordanian individuals. Also, recent results analysis has reported that in the followup intervention, health-related improvements were obtained from self-management programs. The selfmanagement methods increase participants' symptom self-management, knowledge and other self-management behaviors such as testing blood glucose, weight control, self-efficacy and aspects of health status management, very effectively [26]. Many clinical researches confirm the effect of the educational self-efficacy enhancing program interventions in DSE programs among T2DM patients [7,8,10-15].

\section{Pain}

Results of a pre-educational evaluation of the patients' pain levels, showed that the majority of the participants in both groups were having different intensities of pain ranging from moderate to severe. According to a cohort research conducted in the U.K. by Abbott et al. (2011), the results revealed that the painful symptoms occurred in $60 \%$ of patients with severe neuropathy and $26 \%$ of patients without neuropathy [27]. According to pain intensity, in a cross-sectional research that was conducted by Van Acker et al (2009), 61\% of patients had moderate-intensity pain [28]. While a research from the same region was conducted in French by Bouhassira et. al (2013) using the NRS revealed that $76.2 \%$ of patients are having moderate to severe intensity pain [29]. The difference in the reported neuropathic pain characteristics from all over the world can be related to different populations of the researches and the different screening tools that are used to assess DPNP.

In our research, the research group participants who attended the educational self-efficacy enhancement program reported better pain management as perceived by comparing the pretest and posttest means showing improvement after exposure to the educational program. Foot care, control of $\mathrm{HbA} 1 \mathrm{c} \%$ and exercise and lifestyle behaviors affect diabetes multiuse patients in their good pain management, according to most researches [28-31].

\section{Quality of Life}

In a pre-educational evaluation, results showed that the quality of life scores mean was showing a low QoL level. Also, the results of the research revealed that most DPNP participants have reported a problem in discomfort, mobility, usual activity, self-care and anxiety or/and depression. These results of this research were concordant with those from other epidemiological researches, where DPNP patients had significantly lower QoL than those without DPNP. For example, according to a research by Davies et al. (2006), they found that patients who developed DPNP had poorer quality of life [30]. Similar results were found in a research by Van Acker et al (2009). The results revealed that DPNP patients were more likely to report problems in mental alterations and physical activities than those without DPNP, which may account for their lower QoL scores [28]. In a more recent research 
conducted in France, the results showed that DPNP was associated with disturbances in sleep, depression and higher anxiety levels [29]. Another recent research that agrees with the results of our research was performed in South Africa. In this research, the results reported that DPNP has a negative impact on QoL [31].

This research found that the research group participants who attended the educational self-efficacy enhancement program reported a positive impact on QoL. This finding was consistent with the relevant researches [32-38]. On the contrary, data obtained from a research in Saudi Arabia showed that results were not significantly associated with the effect of the educational program and QoL among T2DM diabetic patients [39]. Similarly, a research was conducted in Taiwan failed to show any significant association between the effect of the educational program and QoL among T2DM patients [40]. However, the variation in magnitude between these findings and others may be attributed to either the characteristics of the research's participants or the differences in sample size.

\section{Patient Satisfaction}

Patient satisfaction means that a score of the research group participants showed a high level of satisfaction from educational intervention. Numerous clinical researches confirm the effect of the educational self-efficacy enhancing program interventions in high levels of satisfaction among diabetic patients [16-19]. Therefore, conscientious steps to improve patient engagement and satisfaction are vital for improving the quality of patient care and conveying the important message that healthcare providers are respected and valued as persons.

\section{Limitations}

Some limitations may be recognized regarding the conduction of this research. Although the focus of this research was to investigate DPNP among adult patients, data collection lacks identifying if patients were taking pain pharmacological and non-pharmacological therapies.

\section{Conclusion And Recommendations}

This research found that the self-efficacy enhancement program had a positive impact on DPNP patients' satisfaction, QoL, self-efficiency behaviors and pain levels. Consequently, in order to promote patients' self-care behaviors, it is crucial to improve their self-efficacy behaviors and modification of lifestyle and behavioral changes such as appropriate diet, encouragement to stop smoking, reduce weight, exercise and regularly visit treating physicians during a nursing career. Future researches are recommended to include patients from different health care sectors in Jordan and other health care facilities.

\section{References}

1. Fowler M. Microvascular and macrovascular complications of diabetes. Clinical diabetes, 2008; $26(2): 77-82$. https://doi.org/10.2337/diaclin.26.2.77.

2. Neuropathies D. The nerve damage of diabetes. US Department of Health and Human Services;

3. Tesfaye S \& Selvarajah D. Advances in the epidemiology, pathogenesis and management of diabetic peripheral neuropathy. Diabetes/metabolism research and reviews, 2012; (28): 8-14. https://doi.org/10.1002/dmrr.2239.

4. Treede R. The International Association for the Research of Pain definition of pain: as valid in 2018 as in 1979 , but in need of regularly updated footnotes. Pain reports, 2018; 3(2). doi: 1097/PR9.0000000000000643. 
5. Hall G, Morant S, Carroll D, Gabriel Z, McQuay H. An observational descriptive research of the epidemiology and treatment of neuropathic pain in a UK general population. BMC Family Practice, 2013; 14(1): 28. https://doi.org/10.1186/1471-2296-14-28

6. Gilron, I., Baron, R., \& Jensen, T. (2015, April). Neuropathic pain: principles of diagnosis and treatment. In Mayo Clinic Proceedings (Vol. 90, No. 4, pp. 532-545). Elsevier. https://doi.org/10.1016/j.mayocp.2015.01.018.

7. Atak N, Gurkan T, Kose, K. The effect of education on knowledge, self-management behaviors and self-efficacy of patients with type 2 diabetes. Australian Journal of Advanced Nursing, 2008; 26(2):66. Availability: <https://search.informit.com.au/documentSummary;dn=198857737071665;res=IELHEA> ISSN: 0813-0531.

8. Al-Khawaldeh O, Al-Hassan M, Froelicher E. Self-efficacy, self-management and glycemic control in adults with type 2 diabetes mellitus. Journal of Diabetes and its Complications, 2012; 26(1): 10-16. https://doi.org/10.1016/j.jdiacomp.2011.11.002.

9. Mohebi S, Azadbakht L, Feizi A, Sharifirad G, \& Kargar M. Review the key role of self-efficacy in diabetes care. Journal of education and health promotion, 2013; (2). doi: 10.4103/2277-9531.115827.

10. Sharoni S, Rahman H, Minhat H, Shariff-Ghazali S, Ong M. The effects of self-efficacy enhancing program on foot self-care behavior of older adults with diabetes: A randomized controlled trial in an elderly care facility, Peninsular Malaysia. PloS one, 2018; 13(3): e0192417. doi: 10.1371/journal.pone.0192417.

11. Moein M, Aghajani M, Ajorpaz N, Khorasanifar L. Effect of an empowerment program on self-efficacy of patients with type 2 diabetes. Iranian Red Crescent Medical Journal, 2017; 19(1). DOI: 10.5812/ircmj.29252.

12. Tan C, Cheng K, Hwang S, Zhang N, Holroyd E, Wang W. Effect of a Diabetes Self-Efficacy Enhancing Program on Older Adults with Type 2 Diabetes: A Randomized Controlled Trial. Clinical nursing research, 2018; 1054773818792480. https://doi.org/10.1177/1054773818792480.

13. Moriyama M, Nakano M, Kuroe Y, Nin K, Niitani M, Nakaya T. Efficacy of a self-management education program for people with type 2 diabetes: results of a 12-month trial. Japan Journal of Nursing Science, 2009; 6(1): 51-63. https://doi.org/10.1111/j.1742-7924.2009.00120.x.

14. Wu S, Driver V, Wrobel J, Armstrong D. Foot ulcers in the diabetic patient, prevention and treatment. Vascular health and risk management, 2007; 3(1): 65. PMID: 17583176.

15. Sarkar U, Fisher L, Schillinger D. Is self-efficacy associated with diabetes self-management across race/ethnicity and health literacy? Diabetes care, 2006; 29(4): 823-829.

https://doi.org/10.2337/diacare.29.04.06.dc05-1615.

16. De Simone S, Planta A, Cicotto G. The role of job satisfaction, work engagement, self-efficacy and agentic capacities on nurses' turnover intention and patient satisfaction. Applied Nursing Research, 2018; (39): 130 140. https://doi.org/10.1016/j.apnr.2017.11.004.

17. Krass I, Delaney C, Glaubitz S, Kanjanarach T. Measuring patient satisfaction with diabetes disease state management services in community pharmacy. Research in Social and Administrative Pharmacy, 2009; 5(1): 31-39. https://doi.org/10.1016/j.sapharm.2008.05.006.

18. Zanetti M, Otero L, Biaggi M, Santos M, Péres D, Guimarães F. Satisfaction of diabetes patients under followup in a diabetes education program. Revista latino-americana de enfermagem, 2007; 15(4): 583-589. https://doi.org/10.1590/S0104-11692007000400010.

19. Garrett D \& Bluml B. (2005). Patient self-management program for diabetes: first-year clinical, humanistic and economic outcomes. Journal of the American Pharmacists Association, 2005; 45(2): 130-137. https://doi.org/10.1331/1544345053623492.

Page 10/21 
20. Bandura A. Self-efficacy mechanism in human agency. American psychologist, 1982; 37(2): 122. https://doi.org/10.1037/0003-066X.37.2.122.

21. Lorig K, Ritter P, Villa F, Armas J. Community-based peer-led diabetes self-management. The Diabetes Educator, 2009; 35(4): 641-651.

https://doi.org/10.1177/0145721709335006.https://www.selfmanagementresource.com/docs/pdfs/English__self-efficacy_diabetes.pdf.

22. Al-Amer R, Ramjan L, Glew P, Randall S, Salamonson Y. Self-efficacy, depression and self-care activities in adult Jordanians with type 2 diabetes: the role of illness perception. Issues in mental health nursing, 2016; 37(10): 744-755. PMID:27484761. DOI:10.1080/01612840.2016.1208692.

23. EuroQol G. EuroQol--a new facility for the measurement of health-related quality of life. Health policy (Amsterdam, Netherlands), 1990; 16(3): 199. https://doi.org/10.1016/0168-8510(90)90421-9.

24. Abu-Shennar J, Bebis H, Bayraktar N. EQ-5D OF ADULT DIABETIC PATIENTS WITH PERIPHERAL NEUROPATHY PAIN: ARABIC VALIDITY AND RELIABILITY RESEARCH OF LIFE QUALITY SCALEA. In 28th Şubat-1st Mart, Kibris. 17th NÖROPATIKK AĞRI SEMPOZYUMU Conference, 2020; 9.

25. American Diabetes Association. Classification and diagnosis of diabetes. Diabetes care, 2017; 40(Supplement 1): S11-S24. https://doi.org/10.2337/dc17-S005.

26. Anekwe T\& Rahkovsky I. Self-Management: A Comprehensive Approach to Management of Chronic Conditions. American Journal of Public Health, 2018; 108(S6):S430-S436.

https://doi.org/10.2105/AJPH.2014.302041r.

27. Abbott A, Malik A, van Ross R, Kulkarni J, Boulton J. Prevalence and characteristics of painful diabetic neuropathy in a large community-based diabetic population in the UK. Diabetes Care, 2011; 34(10): 22202224. https://doi.org/10.2337/dc11-1108.

28. Van Acker K, Bouhassira D, De Bacquer D, Weiss S, Matthys K, Raemen H, et al. Prevalence and impact on the quality of life of peripheral neuropathy with or without neuropathic pain in type 1 and type 2 diabetic patients attending hospital outpatients' clinics. Diabetes \& metabolism, 2009; 35(3): 206-213. https://doi.org/10.1016/j.diabet.2008.11.004.

29. Bouhassira D, Letanoux M, \& Hartemann A. Chronic pain with neuropathic characteristics in diabetic patients: A French cross-sectional research. PLoS One, 2013; 8(9). doi: 10.1371/journal.pone.0074195.

30. Davies M, Brophy S, Williams R, Taylor A. The prevalence, severity and impact of painful diabetic peripheral neuropathy in type 2 diabetes. Diabetes care, 2006; 29(7): 1518-1522. https://doi.org/10.2337/dc05-2228.

31. Jacovides A, Bogoshi M, Distiller L, Mahgoub E, Omar M, Tarek I, Wajsbrot D. An epidemiological research to assess the prevalence of diabetic peripheral neuropathic pain among adults with diabetes attending private and institutional outpatient clinics in South Africa. Journal of International Medical Research, 2014; 0300060514525759. https://doi.org/10.1177/0300060514525759.

32. Rasoul A, Jalali R, Abdi A, Salari N, Rahimi M, Mohammadi M. The effect of self-management education through weblogs on the quality of life of diabetic patients. BMC medical informatics and decision making, 2019; 19(1): 205. https://doi.org/10.1186/s12911-019-0941-6.

33. Wattana C, Srisuphan W, Pothiban L, Upchurch S. Effects of a diabetes self-management program on glycemic control, coronary heart disease risk and quality of life among Thai patients with type 2 diabetes. Nursing \& health sciences, 2007; 9(2): 135-141. https://doi.org/10.1111/j.1442-2018.2007.00315.x. 
34. Jiang X, Wang J, Lu Y, Jiang H, Li M. Self-efficacy-focused education in persons with diabetes: a systematic review and meta-analysis. Psychology research and behavior management, 2019; (12): 67. doi:

10.2147/PRBM.S192571.

35. Didarloo A, Shojaeizadeh D, Asl R, Habibzadeh H, Niknami S, Pourali R. Prediction of self-management behavior among Iranian women with type 2 diabetes: application of the theory of reasoned action along with self-efficacy (etra). Iranian Red Crescent Medical Journal, 2012; 14(2): 86. PMID: 22737561.

36. Grey M, Whittemore R, Jeon S, Murphy K, Faulkner M, Delamater A, TeenCope Research Group. Internet psychoeducation programs improve outcomes in youth with type 1 diabetes. Diabetes care, 2013; 36(9): $2475-2482$. https://doi.org/10.2337/dc12-2199.

37. Aghamolaei T, Eftekhar H, Mohammad K, Nakhjavani M, Shojaeizadeh D, Ghofranipour F, Safa O. Effects of a health education program on behavior, $\mathrm{HbA} 1 \mathrm{c}$ and health-related quality of life in diabetic patients. Acta Medica Iranica, 2012; 89-94.

38. Marks R \& Allegrante J. A review and synthesis of research evidence for self-efficacy-enhancing interventions for reducing chronic disability: implications for health education practice (part II). Health promotion practice, 2005; 6(2): 148-156. https://doi.org/10.1177/1524839904266792.

39. Mokabel F, Aboulazm S, Hassan H, Al-Qahtani M, Alrashedi S, Zainuddin F. The efficacy of a diabetic educational program and predictors of compliance of patients with noninsulin-dependent (type 2) diabetes mellitus in Al-Khobar, Saudi Arabia. Journal of family \& community medicine, 2017; 24(3): 164. doi: 10.4103/jfcm.JFCM_45_16.

40. Wu S. Effectiveness of self-management for persons with type 2 diabetes following the implementation of a self-efficacy enhancing intervention program in Taiwan (Doctoral dissertation, Queensland University of Technology).

\section{Tables}

Table 1. Sample characteristics $(\mathrm{N}=72)$. 


\begin{tabular}{|c|c|c|c|}
\hline Variables & $\begin{array}{l}\text { Research group } \\
n=36 \\
\text { No. (\%) }\end{array}$ & $\begin{array}{l}\text { Control group } \\
n=36 \\
\text { No. (\%) }\end{array}$ & P-value \\
\hline Age (in years), mean $( \pm S D)$ & $66.3( \pm 5.5)$ & $60.9( \pm 5.8)$ & 0.052 \\
\hline Gender & & & 0.222 \\
\hline Male & $27(75)$ & $23(63.9)$ & \\
\hline Female & $9(25)$ & $13(36.1)$ & \\
\hline Educational Level & & & 0.185 \\
\hline High School or Less & $15(41.7)$ & $8(22.2)$ & \\
\hline Diploma & $9(25)$ & $14(38.9)$ & \\
\hline Bachelor Degree or Higher & $12(33.3)$ & $14(38.9)$ & \\
\hline Smoking status & & & 0.168 \\
\hline No & $25(69.4)$ & $22(61.1)$ & \\
\hline Yes & $11(30.6)$ & $14(38.9)$ & \\
\hline Body Mass Index $(\mathrm{BMI})\left(\mathrm{Kg} / \mathrm{m}^{2}\right)^{\star}$, mean $( \pm \mathrm{SD})$ & $37.59( \pm 4.8)$ & $39.44( \pm 4.9)$ & 0.343 \\
\hline Monthly Family Income (in JD), mean ( \pm SD) & $338.5( \pm 104.8)$ & $385.3( \pm 111.2)$ & 0.173 \\
\hline
\end{tabular}

* = Normal: $18.5-24.9 \mathrm{~kg} / \mathrm{m}^{2}$; overweight: $25-29.9 \mathrm{~kg} / \mathrm{m}^{2}$; obese: $\geq 30 \mathrm{~kg} / \mathrm{m}^{2}$

Table 2. Preeducational evaluation of Pain (NRS) scores, Self-efficacy, and QoL, and Best Imagined Health Status $(\mathrm{N}=72)$. 
NRS score (out of 10)

\section{Self-efficacy overall score (out of 5)}

How confident do you feel that you can eat your meals every 4 to 5 hours every day, including

\section{Self-efficacy Q2 score (out of 5)}

How confident do you feel that you can follow your diet when you have to prepare or share food with other people who do not have diabetes?

\section{Self-efficacy Q3 score (out of 5)}

How confident do you feel that you can choose the appropriate foods to eat when you are hungry

(for example, snacks)?

\section{Self-efficacy Q4 score (out of 5)}

How confident do you feel that you can exercise 15 to 30 minutes, 4 to 5 times a week?

\section{Self-efficacy Q5 score (out of 5)}

How confident do you feel that you can do something to prevent your blood sugar level from

dropping when you exercise?

\section{Self-efficacy Q6 score (out of 5)}

How confident do you feel that you know what to do when your blood sugar level goes higher or lower than it should be?

\section{Self-efficacy Q7 score (out of 5)}

How confident do you feel that you can judge when the changes in your illness mean you should visit the doctor?

\section{Self-efficacy Q8 score (out of 5)}

How confident do you feel that you can control your diabetes so that it does not interfere with the things you want to do?

\section{QoL overall score (out of 4)}

QoL Mobility domain score (out of 4)

QoL Self-care domain score (out of 4 ) 
Table 3. Comparison of NRS score, QoL overall and domain scores, Best Imagined Health Status and Self-efficacy overall score and domain scores between preeducational and posteducational evaluation among research group $(n=36)$. 


\begin{tabular}{|c|c|c|c|c|}
\hline Item & $\begin{array}{l}\text { Pre-Education Research } \\
\text { Group, mean }( \pm S D)\end{array}$ & $\begin{array}{l}\text { Post-Education Research } \\
\text { Group, mean }( \pm S D)\end{array}$ & T-test & P-value \\
\hline NRS score (out of 10 ) & $6.53( \pm 3.33)$ & $5.08( \pm 1.46)$ & 5.694 & $0.02^{\star}$ \\
\hline $\begin{array}{l}\text { QoL overall score (out of } \\
\text { 4) }\end{array}$ & $1.07( \pm 0.61)$ & $3.12( \pm 0.70)$ & 176.242 & $0.000 * *$ \\
\hline $\begin{array}{l}\text { QoL Mobility domain } \\
\text { score (out of } 4 \text { ) }\end{array}$ & $1.11( \pm 0.71)$ & $3.03( \pm 0.81)$ & 114.212 & $0.000 * *$ \\
\hline $\begin{array}{l}\text { QoL Self-care domain } \\
\text { score (out of 4) }\end{array}$ & $1.14( \pm 0.72)$ & $3.08( \pm 0.91)$ & 101.240 & $0.000 * *$ \\
\hline $\begin{array}{l}\text { QoL Activity domain } \\
\text { score (out of 4) }\end{array}$ & $1.36( \pm 0.68)$ & $3.17( \pm 0.91)$ & 90.665 & $0.000 * *$ \\
\hline $\begin{array}{l}\text { QoL Discomfort domain } \\
\text { score (out of } 4 \text { ) }\end{array}$ & $1.31( \pm 0.71)$ & $3.42( \pm 0.77)$ & 146.281 & $0.000 * *$ \\
\hline $\begin{array}{l}\text { QoL Depression domain } \\
\text { score (out of } 4 \text { ) }\end{array}$ & $0.44( \pm 0.61)$ & $2.89( \pm 0.92)$ & 177.382 & $0.000 * *$ \\
\hline $\begin{array}{l}\text { Best Health Status } \\
\text { Imagined (out of 100) }\end{array}$ & $78.27( \pm 12.31)$ & $86.67( \pm 13.09)$ & 97.644 & $0.000 * *$ \\
\hline $\begin{array}{l}\text { Self-efficacy overall score } \\
\text { (out of } 5 \text { ) }\end{array}$ & $1.43( \pm 0.16)$ & $3.46( \pm 0.59)$ & 386.545 & $0.000 * *$ \\
\hline $\begin{array}{l}\text { Self-efficacy Q1 score } \\
\text { (out of 5) }\end{array}$ & $1.00( \pm 0.01)$ & $3.31( \pm 0.89)$ & 242.327 & $0.000 * *$ \\
\hline $\begin{array}{l}\text { Self-efficacy Q2 score } \\
\text { (out of 5) }\end{array}$ & $1.39( \pm 0.50)$ & $3.42( \pm 0.77)$ & 165.356 & $0.000 * *$ \\
\hline $\begin{array}{l}\text { Self-efficacy Q3 score } \\
\text { (out of 5) }\end{array}$ & $1.40( \pm 0.49)$ & $3.44( \pm 0.69)$ & 217.062 & $0.000 * *$ \\
\hline $\begin{array}{l}\text { Self-efficacy Q4 score } \\
\text { (out of 5) }\end{array}$ & $1.00( \pm 0.01)$ & $3.25( \pm 0.87)$ & 238.458 & $0.000 * *$ \\
\hline $\begin{array}{l}\text { Self-efficacy Q5 score } \\
\text { (out of 5) }\end{array}$ & $1.31( \pm 0.47)$ & $3.53( \pm 0.61)$ & 301.887 & $0.000 * *$ \\
\hline $\begin{array}{l}\text { Self-efficacy Q6 score } \\
\text { (out of 5) }\end{array}$ & $1.53( \pm 0.51)$ & $3.53( \pm 0.61)$ & 229.671 & $0.000 * *$ \\
\hline $\begin{array}{l}\text { Self-efficacy Q7 score } \\
\text { (out of 5) }\end{array}$ & $2.36( \pm 0.64)$ & $3.83( \pm 0.65)$ & 93.190 & $0.000^{* *}$ \\
\hline $\begin{array}{l}\text { Self-efficacy Q8 score } \\
\text { (out of 5) }\end{array}$ & $1.42( \pm 0.50)$ & $3.36( \pm 0.64)$ & 206.627 & $0.000^{* *}$ \\
\hline
\end{tabular}

* = significance level $0.05 ; * *$ significance level 0.01

Table 4. 2-step Multiple Linear Regression Model of Variance in Self-Efficacy Score as predicted by (Step 1: Age, Gender, Income, and Type of Treatment) and (Step 2: Intervention) ( $\mathrm{N}=72$ ). 


\begin{tabular}{|c|c|c|c|c|c|c|c|}
\hline & \multirow[t]{2}{*}{ Factor } & \multirow{2}{*}{$\begin{array}{l}\text { Unstandardized } \\
\text { B }\end{array}$} & \multicolumn{2}{|c|}{$95 \% \mathrm{Cl}$ of $\mathrm{B}$} & \multirow{2}{*}{$\begin{array}{l}\text { Standardized } \\
\text { Beta }\end{array}$} & \multirow[t]{2}{*}{ T-test } & \multirow[t]{2}{*}{ P-value } \\
\hline & & & Lower & Upper & & & \\
\hline \multirow[t]{4}{*}{$\begin{array}{l}\text { Step } \\
1\end{array}$} & Age & 0.109 & $\overline{0} .029$ & 0.247 & -0.080 & 0.408 & 0.686 \\
\hline & Gender & -0.777 & $\overline{2} .952$ & 1.398 & 0.035 & 0.190 & 0.850 \\
\hline & Income & -0.003 & $\overline{-} 0.005$ & $\overline{-} 0.001$ & 0.019 & 0.085 & 0.933 \\
\hline & Type of Treatment & 1.025 & 0.002 & 2.049 & -0.151 & $\overline{-} 0.673$ & 0.506 \\
\hline \multicolumn{8}{|c|}{ Step 1 ANOVA $F(d f)=.253(4), p=.906, R=.184, R^{2}=.034$} \\
\hline $\begin{array}{l}\text { Step } \\
2\end{array}$ & $\begin{array}{l}\text { Educational } \\
\text { Intervention }\end{array}$ & 1.494 & 0.913 & 2.075 & 0.903 & 8.861 & $0.000^{* *}$ \\
\hline
\end{tabular}

Cl: Confidence Interval

** statistically significant, $p>0.05$

Table 5. 2-step Multiple Linear Regression Model of Variance in QoL Score as predicted by (Step 1: Age, Gender, Income, and Type of Treatment) and (Step 2: Intervention) $(\mathrm{N}=72)$.

\begin{tabular}{|c|c|c|c|c|c|c|c|}
\hline & \multirow[t]{2}{*}{ Factor } & \multirow{2}{*}{$\begin{array}{l}\text { Unstandardized } \\
\text { B }\end{array}$} & \multicolumn{2}{|c|}{$95 \% \mathrm{Cl}$ of $\mathrm{B}$} & \multirow{2}{*}{$\begin{array}{l}\text { Standardized } \\
\text { Beta }\end{array}$} & \multirow[t]{2}{*}{ t-test } & \multirow[t]{2}{*}{ P-value } \\
\hline & & & Lower & Upper & & & \\
\hline \multirow[t]{4}{*}{$\begin{array}{l}\text { Step } \\
1\end{array}$} & Age & 0.133 & $\overline{0} .014$ & 0.114 & 0.290 & 1.548 & 0.133 \\
\hline & Gender & 0.384 & $\overline{-} 1.330$ & 0.692 & -0.156 & $\overline{0} .884$ & 0.384 \\
\hline & Income & 0.727 & $\overline{0} .986$ & 0.992 & -0.076 & $\overline{-}-353$ & 0.727 \\
\hline & Type of Treatment & 0.689 & $\overline{0} .652$ & 0.299 & 0.086 & 0.404 & 0.689 \\
\hline \multicolumn{8}{|c|}{ Step 1 ANOVA F $(d f)=.253(4), p=.906, R=.184, R^{2}=.034$} \\
\hline $\begin{array}{l}\text { Step } \\
2\end{array}$ & $\begin{array}{l}\text { Educational } \\
\text { Intervention }\end{array}$ & 1.504 & 0.811 & 1.991 & 0.807 & 9.068 & $0.000^{\star *}$ \\
\hline
\end{tabular}

Cl: Confidence Interval

** statistically significant, $p>0.05$ 
Table 6. Research group participant's correlation between pain scores, self-efficacy score, and QoL score both in the preeducational and posteducational evaluation $(n=36)$.

\begin{tabular}{|c|c|c|c|c|}
\hline Variable & Spearman's rho & Pain Score & Self-efficacy Score & QoL Score \\
\hline \multicolumn{5}{|c|}{ Pre-Educational Evaluation } \\
\hline \multirow[t]{2}{*}{ Pain Score } & Correlation Coefficient & 1.000 & -0.075 & -0.188 \\
\hline & P-value & . & 0.662 & 0.271 \\
\hline \multirow[t]{2}{*}{ Self-efficacy Score } & Correlation Coefficient & -0.075 & 1.000 & -0.029 \\
\hline & P-value & 0.662 & . & 0.865 \\
\hline \multirow[t]{2}{*}{ QoL Score } & Correlation Coefficient & -0.188 & -0.029 & 1.000 \\
\hline & P-value & 0.271 & 0.865 & . \\
\hline \multicolumn{5}{|c|}{ Post-Educational Evaluation } \\
\hline \multirow[t]{2}{*}{ Pain Score } & Correlation Coefficient & 1.000 & 0.059 & -0.039 \\
\hline & P-value & . & 0.731 & 0.820 \\
\hline \multirow[t]{2}{*}{ Self-efficacy Score } & Correlation Coefficient & 0.059 & 1.000 & $-0.759 * *$ \\
\hline & P-value & 0.731 & . & 0.000 \\
\hline \multirow[t]{2}{*}{ QoL Score } & Correlation Coefficient & -0.039 & $-0.759 * *$ & 1.000 \\
\hline & P-value & 0.820 & 0.000 & . \\
\hline
\end{tabular}

** = Spearman's rho correlation coefficient is significant at the 0.01 level (2-tailed)

Table 7. Post-educational evaluation research group participants' satisfaction $(n=36)$. 


\begin{tabular}{|c|c|}
\hline Variable & $\mathrm{n}(\%)$ \\
\hline Overall satisfaction score (Out of 5 ), mean ( \pm SD) & $4.33( \pm 0.67)$ \\
\hline \multicolumn{2}{|l|}{ Adheres to the rules of professional appearance } \\
\hline Never & $0(0)$ \\
\hline Low & $0(0)$ \\
\hline Moderate & $2(5.6)$ \\
\hline Good & $15(41.6)$ \\
\hline Very good & $19(52.8)$ \\
\hline \multicolumn{2}{|l|}{ Communicates well with teams' educational programs. } \\
\hline Never & $0(0)$ \\
\hline Low & $0(0)$ \\
\hline Moderate & $2(5.6)$ \\
\hline Good & $18(50)$ \\
\hline Very good & $16(44.4)$ \\
\hline \multicolumn{2}{|c|}{ Communicate well with patients to achieve effective learning } \\
\hline Never & $0(0)$ \\
\hline Low & $0(0)$ \\
\hline Moderate & $3(8.3)$ \\
\hline Good & $14(38.9)$ \\
\hline Very good & $19(52.8)$ \\
\hline \multicolumn{2}{|c|}{ Interacts and participates with activities to improve education } \\
\hline \multicolumn{2}{|l|}{ Never } \\
\hline Low & $0(0)$ \\
\hline Moderate & $0(0)$ \\
\hline Good & $4(11.1)$ \\
\hline \multirow[t]{2}{*}{ Very good } & $12(33.3)$ \\
\hline & $20(55.6)$ \\
\hline \multicolumn{2}{|c|}{ Commitment to good behavior with all elements of the educational process } \\
\hline \multicolumn{2}{|l|}{ Never } \\
\hline Low & $0(0)$ \\
\hline Moderate & $0(0)$ \\
\hline Good & $3(8.3)$ \\
\hline
\end{tabular}




\begin{tabular}{|c|c|}
\hline \multirow[t]{2}{*}{ Very good } & $14(38.9)$ \\
\hline & $19(52.8)$ \\
\hline \multicolumn{2}{|c|}{ Helps change the behavior of patients and encourages them to do so } \\
\hline \multicolumn{2}{|l|}{ Never } \\
\hline Low & $0(0)$ \\
\hline Moderate & $0(0)$ \\
\hline Good & $5(13.9)$ \\
\hline \multirow[t]{2}{*}{ Very good } & $14(38.9)$ \\
\hline & $17(47.2)$ \\
\hline \multicolumn{2}{|c|}{ Commits to the timing, time, and end of the lecture } \\
\hline Never & $0(0)$ \\
\hline Low & $0(0)$ \\
\hline Moderate & $5(13.9)$ \\
\hline Good & $10(27.8)$ \\
\hline Very good & $21(58.3)$ \\
\hline \multicolumn{2}{|c|}{ Participates in the continuous development of information } \\
\hline \multicolumn{2}{|l|}{ Never } \\
\hline Low & $0(0)$ \\
\hline Moderate & $0(0)$ \\
\hline Good & $2(5.6)$ \\
\hline \multirow[t]{2}{*}{ Very good } & $15(41.6)$ \\
\hline & $19(52.8)$ \\
\hline \multicolumn{2}{|c|}{ Communicates with the family of patients in a professional and good way } \\
\hline \multicolumn{2}{|l|}{ Never } \\
\hline Low & $0(0)$ \\
\hline Moderate & $0(0)$ \\
\hline Good & $5(13.9)$ \\
\hline \multirow[t]{2}{*}{ Very good } & $11(30.6)$ \\
\hline & $20(55.5)$ \\
\hline \multicolumn{2}{|c|}{ He constantly develops his performance through continuous training } \\
\hline \multicolumn{2}{|l|}{ Never } \\
\hline Low & $0(0)$ \\
\hline Moderate & $0(0)$ \\
\hline
\end{tabular}


